www.jmscr.igmpublication.org

Impact Factor 5.244

Index Copernicus Value: 83.27

ISSN (e)-2347-176x ISSN (p) 2455-0450

crossref DOI: _http://dx.doi.org/10.18535/jmscr/v4i9.71

Journal Of Medical Science And Clinical Research

\title{
Treatment of Intra Articular Fractures of Distal Radius Using External Fixator: A Short Term Study
}

Authors

\section{Mehmood Ul Hassan Mufti ${ }^{1}$, Sheikh Ajaz ${ }^{2}$, Muhammad Ashraf Khan ${ }^{3}$ \\ Raja Rameez Farooqi ${ }^{4}$, Hilal Ahmad Kotwal ${ }^{5}$}

1,2,3,4,5 Post-Graduate Dept of Orthopaedics Bone and Joint Hospital Brazulla Srinagar Jammu and Kashmir

Corresponding Author

\section{Mehmood Ul Hassan Mufti}

Post Graduate Dept of Orthopaedics Bone and Joint Hospital Brazulla Srinagar Jammu and Kashmir INDIA Email: mehmood.mufti@gmail.com phone no.9622660686

\begin{abstract}
Background: Severely comminuted intra-articular fractures of the distal end of the radius are difficult to treat. Failure to achieve and maintain nearly anatomic restoration can result in pain, instability, and poor function. We report the results of a retrospective study of the use of a standard protocol of closed reduction and external fixation of these fractures.

Methods: Fifty patients underwent closed reduction and external fixation with or without augmentation with $k$-wires. Thirty-three patients required additional $k$-wires. The mean time until the external fixator was removed was seven weeks.

Study Design \& Settings: Observational prospective study at a tertiary care hospital from September 2013 to August 2015.

Results: At a mean of thirteen months postoperatively, the mean arc of flexion-extension was $82 \%$ of that on the uninjured side and the mean grip strength was $83 \%$ of that on the uninjured side. The mean articular step-off was $1 \mathrm{~mm}$ and the radial length was restored to a mean of $11 \mathrm{~mm}$. According to the modified Green and O'Brien clinical rating system, twenty-five had a good or excellent result. Thirteen patients had minor Kirschner-wire-related problems.

Conclusions: Closed reduction and external fixation of intra-articular fractures can restore radiographic parameters to nearly normal values, maintain reduction throughout the period of fracture-healing, and provide satisfactory functional results.
\end{abstract}

\section{Introduction}

Treatment of displaced fractures of the distal end of the radius has changed over the course of time. In the past, closed reduction with immobilization in a plaster cast was considered the treatment of choice. Dr. Abraham Colles, in reference to fractures of the distal aspect of the radius, stated:
"One consolation only remains, that the limb will at some remote period again enjoy perfect freedom in all its motions, and be completely exempt from pain; the deformity, however, will remain undiminished throughout life" 1 severely comminuted intra-articular fractures of the distal end of the radius are challenging to treat. 
Restoration ofcongruity of the articular surface is the most criticalfactor for a good functional result. ${ }^{2-8}$ Restoration of radial length (the distance from the radial styloid process to the distalhead of the ulna), radial tilt angle, and volar tilt angle is alsoimportant $\mathrm{t}^{2-7,9}$. Failure to achieve and maintain nearly anatomicrestoration can lead to degenerative arthritis, distal radioulnar and midcarpal in stability, and ulnar impaction syndrome, with resultant pain, decreased motion and strength, and poorfunction. ${ }^{4,6,10-15}$ We report the results of a prospective study of the useof closed reduction and external fixationof intra-articular fractures in fifty patients who werefollowed for a minimum of one year.

\section{Material \& Methods}

A Prospective observational study of 50 patients was made, who were treated with closed reduction under fluoroscopy, distraction with the external fixator with or without K-wire fixation as deemed necessary. for intra-articular distal radius fractures at the Department of Orthopaedic Surgery, at our tertiary care centre over a period from September 2010 to August 2012. Patients included in the study were adults (Age $20-60$ ), patient with intra articular fractures of distal end of radius (AO Type B/C), all closed and Grade I (Gustillo and Anderson) compound fractures and presenting within 72 hours of injury. Patients with Grade II and III open fracture distal radius, pathological fractures, rheumatoid arthritis, concomitant injuries of same limb, bilateral distal end radius fractures and neurovascular injuries were excluded.

The specific radiographic criterion for considering closed reduction as acceptable was more than a 2mm step-off of the distal articular surface of the radius $^{2,7}$

The fractures were assessed preoperatively by wrist radiographs (PA and LATERAL) and were classified according to the AO/ASIF classification system. Seven patients (14\%) had 23.B2 type of fracture, seventeen patients (34\%) had 23.B3 type of fracture, ten patients (20\%) had 23.C1, eight patients (16\%) had 23.C2 type of fracture and eight patients (16\%) had 23.C3 type of fracture.

\section{Demographic Data}

The fifty patients who were included in the study consisted of twenty-nine men and twenty-one women whoranged in age from eighteen to fiftynine years (mean, thirty-eight years). Thirty patients presented initially at ourinstitution, and twenty was referred secondarily. The dominant wrist was injured in 28 patients and the nondominant wrist, in 22 . The initial injury resulted from a high-energy mechanismin forty patients: fifteen were injured in a fall from aheight; while as twenty-five had injury during a road traffic accident. The injury resulted from a lower-energy mechanismin ten patients: seven fell while walking or running, threewere injured while doing household activity.

\section{Surgical Technique}

A general aesthetic was administered to thirty-one of the fifty patients, and a supra-clavicular block was used in nineteen. The external fixator was initially placed, with use of standard technique ${ }^{11,17}$. Pins were placed in the neck and base of the second metacarpal18. The most distal pin in the radius wasplaced at least $2 \mathrm{~cm}$ from the fracture site, and the proximalpin was placed at least $2 \mathrm{~cm} .{ }^{11,17}$ proximal to the distal pin.

Manual tractionwas placed on the fixator to help to reduce the fractureand to correct radial length and displacement through ligamentotaxis ${ }^{19}$.The reduced position of the fracture fragmentswas checked with fluoroscopy, and it was determined, in thirteen patients, additional $\mathrm{k}$ wires were used to maintain reduction. Satisfactoryreduction with slight distraction of the radiocarpal joint was confirmed with fluoroscopy ${ }^{11}$. The external fixator remained until bone-healing wasdemonstrated on plain radiographs; it was removed at a meanof seven weeks (range, five to nine weeks) postoperatively. Bone-healing was determined radiographically by the appearanceof bridging trabeculae across the fracture site and clinicallyby the fracture site being non-tender to palpation. 
Twenty-three ofthe patients had the Kirschner wires removed when the fixatorwas removed. The wires were removed earlier from ten patients who had pin-track-related problems.

The time from the injury to the definitive operationranged from one to fourteen days (mean, three days)

\section{Postoperative Management}

All patients began active and passive rangeofmotionexercises of the hand, forearm, elbow, and shoulder onthe day after the operation ${ }^{5}$.

\section{Follow-up Assessment}

\section{Fracture Classification}

Fracture classification: Fractures were categorized on preoperative radiographs (without traction or computed tomographic scans) within the AO classification ${ }^{6-9,20-22}$. intra articular Type$\mathrm{B} / \mathrm{C}$ fractures, the most severe within the AO system, are divided into three sub classifications according to whether the comminution ${ }^{4,19,21}$.

\section{Objective Assessment:}

At the final follow-up examination, patients were tested for range of motion, for grip strength with a hand held dynamometer. Measurements of the contra lateral side served as controls ${ }^{8}$.

\section{Subjective Assessment:}

At third, sixth month and at final follow-up visit, a quick dash questionnaire was given and the scoring was done and recorded.

\section{Assessment of Radiographic Parameters:}

Standard guidelineswere utilized to determine selected radiographic parameters, ${ }^{4,5,8,23,24}$ which were analysed on posterioanterior and lateral radiographs made at fiver time points: preoperatively before any reduction manoeuvres, immediately after the operation, at thirdmonths at sixth month and at the final follow-up evaluation. Valuesfor the contralateral side were determined from posterioanterior and lateral radiographs made at the final follow-upexamination. ${ }^{8}$

\begin{tabular}{|c|c|c|c|c|}
\hline Outcome measure & Injured wrist & $\begin{array}{l}\text { unInjured } \\
\text { Wrist }\end{array}$ & $\begin{array}{l}\text { Injured Wrist } \\
\text { Percentage } \\
\text { Uninjured Wrist }\end{array}$ & $\begin{array}{l}\text { as } \\
\text { of }\end{array}$ \\
\hline Extension & $65^{\circ} \pm 11^{\circ}$ & $75^{\circ} \pm 13^{\circ}$ & $87 \%$ & \\
\hline Flexion & $64^{\circ} \pm 9^{\circ}$ & $74^{\circ} \pm 9^{\circ}$ & $86 \%$ & \\
\hline Total arc of flexion-extension & $129^{\circ} \pm 21^{\circ}$ & $149^{\circ} \pm 22^{\circ}$ & $86.5 \%$ & \\
\hline Supination & $78^{\circ} \pm 17^{\circ}$ & $84^{\circ} \pm 7^{\circ}$ & $92 \%$ & \\
\hline Pronation & $85^{\circ} \pm 5^{\circ}$ & $89^{\circ} \pm 15^{\circ}$ & $95 \%$ & \\
\hline Total arc of supination-pronation & $163^{\circ} \pm 22^{\circ}$ & $173^{\circ} \pm 22^{\circ}$ & $94 \%$ & \\
\hline Radial deviation & $22^{\circ} \pm 7$ & $32^{\circ} \pm 6$ & $68 \%$ & \\
\hline Ulnar deviation & $33^{\circ} \pm 6$ & $45^{\circ} \pm 7$ & $73 \%$ & \\
\hline Total arc of radioulnar deviation & $55^{\circ} \pm 13$ & $77^{\circ} \pm 13$ & $71 \%$ & \\
\hline Grip strength & $33 \pm 5 \mathrm{~kg}$ & $45 \pm 7 \mathrm{~kg}$ & $73 \%$ & \\
\hline
\end{tabular}

\section{Results}

The mean duration of follow-up of the fifty patients was thirteen months (range, twelve to eighteen months).

\section{Fracture Outcome:}

\section{Fracture Classification:}

Within the AO classification, Seven patients (14\%) had 23. B2 type of fracture, seventeen patients (34\%) had 23.B3 type of fracture, eight patients (16\%) had 23.C2 type of fracture and eighteen patients (36\%) had 23.C3 type of fracture.

\section{Objective Outcome}

The mean values for range of motion and grip strength for the fifty patients are given in Table I. The mean total arc of flexion-extension at the final follow-upevaluation was $129^{\circ}$ (range, $90^{\circ}$ to 
$\left.140^{\circ}\right), 86 \%$ of the valuefor the uninjured side; the mean total arc of supinationpronationwas $163^{\circ}$ (range, $115^{\circ}$ to $180^{\circ}$ ), $94 \%$ of the valuefor the uninjured side; and the mean total arc of radioulnardeviation was $55^{\circ}$ (range, $30^{\circ}$ to $64^{\circ}$ ), $71 \%$ of the value for the uninjured side. The mean grip strength on the injured side was $33 \mathrm{~kg}$ (range, 21 to $43 \mathrm{~kg}$ ), $73 \%$ of the grip strength on the uninjured side.

\section{Subjective Outcome}

All the patients were satisfied with the outcome. The rating of satisfied, even when given by patients with wrist stiffness and/or moderatepain, reflected the patients' appreciation of the substantialrecovery that they achieved after a severe wrist injury. Allthe patients indicated that they would have the surgeryagain under similar circumstances. Thirty-six patients' reportedno pain at the final follow-up examination and twelve had only mild or occasional pain. Two patients reported moderate but tolerable pain. Fourty-four patients had returned to work by the time ofthe final follow-up evaluation, and ten had resumed their preinjuryemployment. Themean time until the patients returned to work was six months(range, 0.25 to thirteen months).Thirty patients reported that they had participated insports before sustaining the wrist injury. By the time of the finalfollow-up evaluation, all thirty had returned to sports, includingfootball, fishing, cricket, volleyball, and skiing. The mean time until thepatients returned to sports was ten months (range, two tothirty months). The quick dash score at the final follow up was $10.92 \pm 8.52$ as shown in table iii.

TABLE II Radiographic Findings for Fractures of the Distal End of the Radius.

\begin{tabular}{|c|c|c|c|c|c|c|}
\hline \multirow[t]{2}{*}{ Outcome measure } & \multicolumn{5}{|c|}{ Injured wrist } & \multirow[t]{2}{*}{ Injured Wrist ${ }^{*}$} \\
\hline & $\begin{array}{l}\text { Immed. } \\
\text { Preop. }\end{array}$ & $\begin{array}{l}\text { Immed. } \\
\text { Postop. }\end{array}$ & $\begin{array}{l}\text { At } 3 \\
\text { month }\end{array}$ & $\begin{array}{ll}\text { At } & 6 \\
\text { month } & \end{array}$ & $\begin{array}{l}\text { At final } \\
\text { Follow-up }\end{array}$ & \\
\hline Radial tilt angle $\dagger$ (deg) & $11 \pm 6$ & $22 \pm 6$ & $21 \pm 5$ & $21 \pm 4$ & $21 \pm 3$ & $23 \pm 5$ \\
\hline Radial length $\dagger(\mathrm{mm})$ & $3 \pm 5$ & $11 \pm 3$ & $11 \pm 4$ & $11 \pm 2$ & $11 \pm 3$ & $12 \pm 4$ \\
\hline Palmer tilt $\dagger($ deg $)$ & $1 \pm 15$ & $6 \pm 6$ & $6 \pm 4$ & $6 \pm 4$ & $6 \pm 5$ & $11 \pm 7$ \\
\hline Articular Step-off $\uparrow(\mathrm{mm})$ & $3 \pm 4$ & $1 \pm 1$ & $1 \pm 1$ & $1 \pm 1$ & $1 \pm 1$ & $0 \pm 0$ \\
\hline \multicolumn{7}{|c|}{$\begin{array}{l}\text { *The values are given as the mean and standard deviation. } \dagger \text { There was a significant improvement from the } \\
\text { preoperative radiographic examination to that performed immediately postoperatively }(p<0.05) \text { The change in } \\
\text { the palmer tilt angle of the distal part of the radius from the preoperative radiographic examination to that } \\
\text { performed immediately postoperatively was calculated for each fracture with reference to the normal of } 11^{\circ} \text { of } \\
\text { volar tilt }{ }^{4,15,22,25} \text {. }\end{array}$} \\
\hline
\end{tabular}

\section{Radiographic Outcome}

The mean values for radiological parameters for the fifty patients are given in Table ii. Comparison of the injured and uninjured wrists at thefinal follow-up evaluation demonstrated, with the numbersavailable, no significant differences in the mean radial tilt angle, radial length, ulnar variance. (Table II). The meantilt angle of the distal end of the radius for the injured wrists atthe final follow-up visit was significantly less than that for theuninjured wrists.

\begin{tabular}{|c|l|l|l|}
\hline \multicolumn{2}{|c|}{ Table iii. quick DASH Score at 3 months, 6 months and final follow-up(mean) $(\mathbf{n}=\mathbf{5 0})$} \\
\hline \multirow{2}{*}{ quickDASH } & 3 months & 6 months & Final follow-up \\
\cline { 2 - 4 } & $32.5 \pm 7$ & $21.7 \pm 5$ & $10.92 \pm 8$ \\
\hline
\end{tabular}

\section{Outcome of Evaluations with Clinical Rating Systems}

According to the modified clinical scoring system of Green and O'Brien 26, the functional result was excellent for one patientand good for four $(29 \%$ good or excellent results); the resultwas fair for eight patients and poor for four. The meanscore (and standard deviation) was $66.5 \pm 17.3$ points (range, 25 to 90 points). The mean pain score was 20 points (range, 0to 25 points), and the mean 


\section{JMSCR Vol||04||Issue||09||Page 12740-12746||September}

return-to-work score was 21points (range, 0 to 25 points). The quick dash score at the final follow up was $10.92 \pm 8.52$ as shown in table iii.

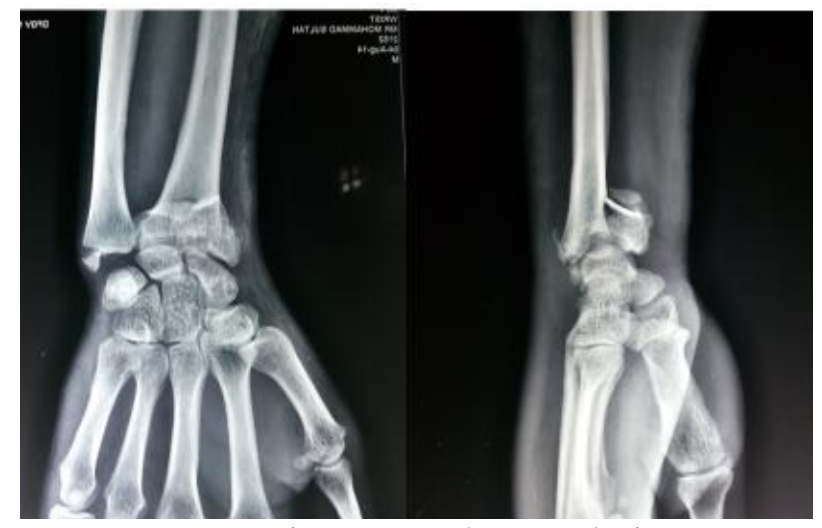

Pre-operative PA and Lateral views

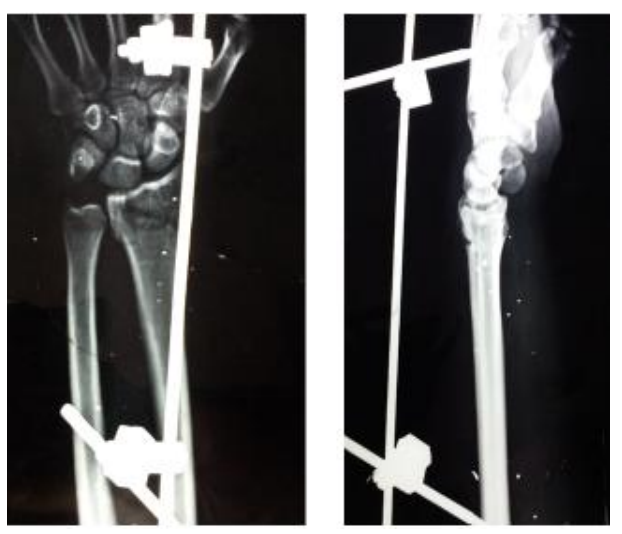

Post-operative PA and Lateral views
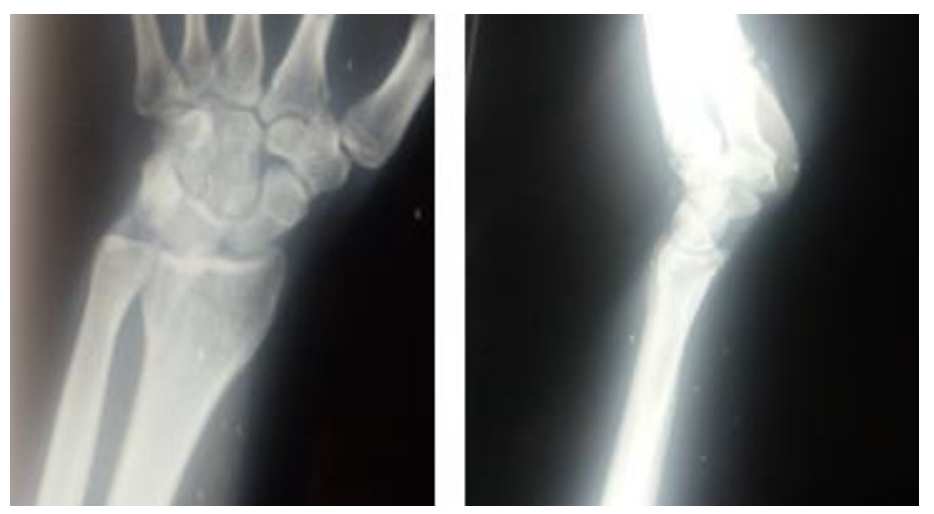

PA and Lateral views at final follow-up


Dorsiflexion and palmarflexion at final follow-up

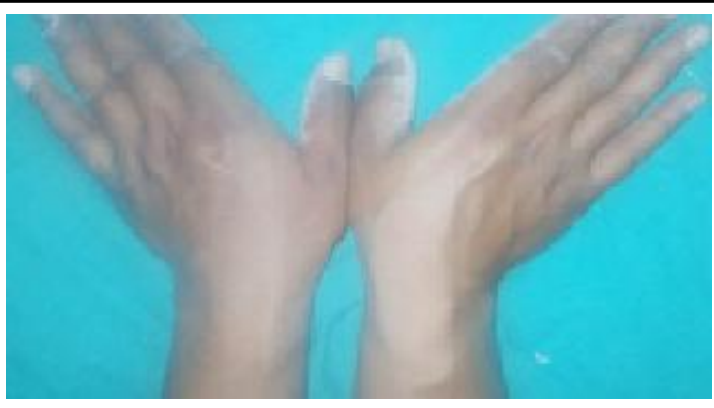

Radial deviation at final follow-up



Ulnar deviation at final follow-up

\section{Discussion}

The findings of our retrospective study confirm the observation by others that anatomic restoration of the articular surface is a critical part of the operative treatment of intra-articular fractures of distal radius and has a direct influence on the final outcome. ${ }^{2,6,7,19}$ Bradway et al. ${ }^{19}$ and Knirk and Jupiter $^{6}$ showed that $>2 \mathrm{~mm}$ of articular incongruity (step-off) was associated with a high prevalence of post-traumatic arthritis and poorer functional results.

The treatment of distal radius fractures has undergone changes owing to the advances in technology. Improved imaging methods providing better understanding of fractures and elucidation of the effects of injury type on fracture formation and factors leading to instability have given way to new fixing methods and materials appropriate for the fracture. Distal radius is important in the kinematics of radiocarpal and radioulnar joints. Hence, anatomical reduction of the articular surface, stable fixation, restoration of the radial length, volar angulation and radial inclination are the prerequisite for good clinical outcome. All this reduces the incidence of post-traumatic osteoarthritis and allow early functional rehabilitation ${ }^{8}$. The degree of disability after distal end radius fracture has been seen to correlate with the 
amount of residual deformity. Treatment options include closed reduction and pinning, bridging and non-bridging external fixation and open reduction with dynamic compression plate (DCP), precontoured locking and non locking plates and screw fixation through a variety of approaches ${ }^{9}$. Failure to reduce intra-articular fractures of the distal radius predisposes to pain, restricted movement and degenerative arthritis. Malposition is related to the radial height, radial angle, volar tilt and the accuracy of intra-articular reduction. ${ }^{10}$ In the treatment of comminuted distal radius intra articular fractures, surgeons may encounter serious complications such as difficult reduction and stabilization, loss of reduction, limitation of range of movement, post traumatic arthritis of the wrist. A brief classification should be made before treating the distal radial fractures. Among various classification systems, the AO classification system is the most suitable one because it reflects the severity of the fracture and helps the surgeon and the patient to know the possible outcomes. ${ }^{11}$ The use of an external fixator alone or in conjunction with percutaneous or limited internal fixation, for unstable fractures of the distal end of the radius has produced good or excellent results. We attribute to these good or excellent results to the early removal of the fixator that allows early range-of-motion exercises and to avoid complications commonly associated with the prolonged use of external fixators. ${ }^{12}$

We believe that intra-articular (AO type-B/C) fractures of the distal part of the radius can be treated by closed reduction and external fixation. Our series demonstrates that this technique, supplemented by k-wires as needed, is a satisfactory treatment that can lead to a high rate of return to work and sports, a high level of patient satisfaction, and a low rate of complications.

\section{References}

1. Colles A. On the Fracture of the Carpal Extremity of the Radius. Edinb Med Surg J. 1814; 10: 182-6.
2. Axelrod TS, McMurtry RY. Open reduction and internal fixation of comminuted, intraarticular fractures of the distal radius. J Hand Surg [Am]. 1990;15:1-11.

3. Bass RL, Blair WF, Hubbard PP. Results of combined internal and external fixation for the treatment of severe AO-C3 fractures of the distal radius. J Hand Surg [Am]. 1995;20:373-81.

4. Jupiter JB. Current concepts review. Fractures of the distal end of the radius. $\mathbf{J}$ Bone Joint Surg Am. 1991;73:461-9.

5. Jupiter JB, Lipton $H$. The operative treatment of intraarticular fractures of the distal radius. ClinOrthop. 1993;292:48-61.

6. Knirk JL, Jupiter JB. Intra-articular fractures of the distal end of the radius in young adults. J Bone Joint Surg Am. 1986;68:647-59.

7. Missakian ML, Cooney WP, Amadio PC, Glidewell HL. Open reduction and internal fixation for distal radius fractures. J Hand Surg [Am]. 1992;17:745-55.

8. Trumble TE, Schmitt SR, Vedder NB. Factors affecting functional outcome of displaced intra-articular distal radius fractures. J Hand Surg [Am]. 1994;19:32540.

9. Bartosh RA, Saldana MJ. Intraarticular fractures of the distal radius: a cadaveric study to determine if ligamentotaxis restores radiopalmar tilt. J Hand Surg [Am]. 1990;15:18-21.

10. Cooney WP 3rd, Dobyns JH, Linscheid RL. Complications of Colles' fractures. J Bone Joint Surg Am. 1980;62:613-9.

11. Edwards GS Jr. Intra-articular fractures of the distal part of the radius treated with the small AO external fixator. J Bone Joint Surg Am. 1991;73:1241-50.

12. Leung KS, Shen WY, Tsang HK, Chiu $\mathrm{KH}$, Leung PC, Hung LK. An effective treatment of comminuted fractures of the distal radius. $\mathrm{J}$ Hand Surg [Am]. 1990;15:11-7. 
13. Melone CP Jr. Open treatment for displaced articular fractures of the distal radius. ClinOrthop. 1986;202:103-11.

14. Taleisnik J, Watson HK. Midcarpal instability caused by malunited fractures of the distal radius. J Hand Surg [Am]. 1984; 9:350-7.

15. Weber SC, Szabo RM. Severely comminuted distal radial fracture as an unsolved problem: complications associated with external fixation and pins and plaster techniques. J Hand Surg [Am]. 1986; 11:157-65.

16. Yen ST, Hwang CY, Hwang MH. A semiinvasive method for articular Colles' fractures. ClinOrthop. 1991;263:154-64

17. Nakata RY, Chand Y, Matiko JD, Frykman GK, Wood VE. External fixators for wrist fractures: a biomechanical and clinical study. J Hand Surg [Am]. 1985; 10:845-51.

18. Jenkins NH, Jones DG, Johnson SR, Mintowt-Czyz WJ. External fixation of Colles' fractures. An anatomical study. J Bone Joint Surg Br. 1987;69:207-11.

19. Bradway JK, Amadio PC, Cooney WP. Open reduction and internal fixation of displaced, comminuted intra-articular fractures of the distal end of the radius. $\mathbf{J}$ Bone Joint Surg Am. 1989;71:839-47

20. Cooney WP 3rd, Linscheid RL, Dobyns JH. External pin fixation for unstable Colles' fractures. J Bone Joint Surg Am. 1979;61:840-5.

21. Fernandez DL, Geissler WB. Treatment of displaced articular fractures of the radius. $\mathrm{J}$ Hand Surg [Am]. 1991;16:375-84.

22. Szabo RM, Weber SC. Comminuted intraarticular fractures of the distal radius. ClinOrthop. 1988;230:39-48.

23. Nattrass GR, King GJ, McMurtry RY, Brant RF. An alternative method for determination of the carpal height ratio. $\mathrm{J}$ Bone Joint Surg Am. 1994;76:88-94.
24. Youm Y, McMurtry RY, Flatt AE, Gillespie TE. Kinematics of the wrist. I. An experimental study of radio-ulnar deviation and flexion-extension. $\mathrm{J}$ Bone Joint Surg Am. 1978;60:423-31.

25. Sanders RA, Keppel FL, Waldrop JI. External fixation of distal radial fractures: results and complications. J Hand Surg [Am]. 1991;16:385-91. 